\title{
Thermal degradation analysis of pongamia pinnata oil as alternative liquid dielectric for distribution transformer
}

\author{
T MARIPRASATH* and V KIRUBAKARAN \\ Rural Energy Centre, The Gandhigram Rural Institute - Deemed University, Gandhigram, Tamilnadu 624302, \\ India \\ e-mail: ts.mariprasath@gmail.com; kirbakaran@yahoo.com
}

MS received 15 July 2015; revised 16 March 2016; accepted 18 March 2016

\begin{abstract}
In this paper the feasibility of non-edible pongamia pinnata oil (PPO) as an alternative liquid dielectric which can be used in distribution transformers is examined. Hence, electrical, physical and chemical properties have been measured for thermally aged (with and without catalytic added) pongamia pinnata oil (PPO) and mineral oil (MO), sampled at $110^{\circ} \mathrm{C}$ for 180 days (according to IEC and IS standard). The experiment results show that, electrical properties of pongamia pinnata oil with catalytic (PPOWC) are better than those of mineral oil with catalytic (MOWC). Whereas, the viscosity and density of PPOWC sample is much higher at all sampling intervals, so that care must be taken for cooling tube design of transformer. Furthermore, for all aging period the total acid content in MOWC oil samples is very low compared to PPOWC. However, these are higher molecular weight acid which is beneficial than lower molecular weight acid generated by MOWC oil samples.
\end{abstract}

Keywords. Distribution transformer; liquid dielectric; breakdown strength; dielectric dissipation factor; dielectric constant.

\section{Introduction}

The liquid dielectrics used in the distribution transformer (DT), perform two important functions, viz., act as an insulation medium and maintain the operating temperature of the transformer within the limit. Over 100 years, mineral oil (MO) is used as the liquid dielectric in the transformers. Due to its physicochemical and electrical properties it is suitable for transformer application and also it is of low cost. However, the negative aspects of MO are low flash point, fire point and dielectric strength. In addition to the above, MO is extracted from fossil fuel and it is rapidly decreasing nowadays. Being a lesser biodegradable oil, it does not satisfy the newer environmental laws [1,2].

The low flash, fire point and breakdown strength can be rectified using a higher molecular weight hydrocarbon, but, the viscosity of oil is high, which reduces the heat ability transfer of oil. In future, biodegradable synthetic esters developed by organic components are synthesized from organic acids and alcohols. But these esters have higher viscosity and it is expensive. The silicon oil was developed in 1970, which has high fire point, very low pour point and it is not affected by oxidation. But it has higher viscosity at low temperature. Also, the Silicon oil contains methyl polysiloxanes which generates Formaldehyde at around 300 degree Fahrenheit and it is hazardous to living organism [3].

*For correspondence
Since 1990s, vegetable oil is being used in distribution transformers, because its physical, chemical and electrical properties satisfy the standard requirements as an insulating oil for transformers. Vegetable oils have a triglyceride structure, which can be classified according to their fatty acid composition saturated and unsaturated (mono-, Di- and Tri-fatty acid). These fatty acids are deciding factor for quality of oil, such as physicochemical and electrical properties of the oil. By contrast, saturated fatty acid oil shows high viscosity, high freezing point, pour point, but, it has low oxidation stability and low dielectric strength. The triple unsaturated fatty acid exhibits a lower viscosity and also it is unstable property. While, the poly unsaturated fatty acids oil possesses good oxidation stability $[4,5]$.

Initially, we performed thermal degradation analysis of pongamia pinnata oil (PPO) using weight balance method. Results show that it has the best thermal withstand ability [6]. Subsequently the breakdown strength, viscosity and water content analysis are performed to without catalytic added PPO sample. Results show that the average breakdown strength of PPO is higher than that of conventionally used MO, whereas viscosity of PPO is significantly higher than that of MO. This gradually decreases as operating temperature increases. Also, the water content of PPO significantly decreased with increased aging period [7].

In this paper, the electrical property of the oil includes the breakdown strength, dielectric dissipation factor, dielectric constant, and specific resistivity; the physical 
properties of the oil include the flash point, fire point, pour point, and viscosity; and the chemical properties include the acidity and water content which has been measured according to IEC and BIS. Then the results are compared with traditionally used MO. Also, we carry out thermal degradation analysis with and without catalytic oil samples.

\section{Sample preparation for critical properties}

The mineral oil kraft paper, pressboard and copper wire were obtained from the associated transformers and the PPO oil is obtained from the local market. The experimental work has been carried out for three types of oil samples. The first sample is the fresh oil, the second sample is prepared without catalyst, and the third sample is prepared with catalyst. The catalyst is prepared from solid insulating materials (copper wire, kraft paper and pressboard) having the thickness of about $0.3 \mathrm{~mm}$, diameter of $42 \mathrm{~mm}$ and the area of copper wire is $50 \mathrm{~cm}^{2}$. Initially the solid insulating material is dried in a vacuum chamber at $90^{\circ} \mathrm{C}$ for $40 \mathrm{~h}$. Subsequently, the PPO is poured into the vacuum box, then it is adjusted to a temperature of about $40^{\circ} \mathrm{C}$, subsequently, the oil is allowed to remain in the vacuum box for about $12 \mathrm{~h}$. The initial moisture content of the MO sample is $5 \mathrm{mg} / \mathrm{kg}$ and the PPO oil is $17.8 \mathrm{mg} / \mathrm{kg}$ respectively. The ratio between the oil and the solid insulating material is $10: 1$. Then the samples are placed in a hot air oven at $110^{\circ} \mathrm{C}$ for about 180 days to investigate the aging performance of insulating oil $[8,9]$.

\section{Experimental results}

Based on the experimental results critical properties of PPO have satisfied the Indian and International standard requirements as a liquid insulating material as shown in table 1 . From the experimental analysis it is seen that the electrical and physicochemical properties are better than the conventionally used MO. However, thermal degradation analysis of oil samples is discussed in the following section.

\section{Thermal degradation analysis of PPO}

\subsection{Breakdown strength $(B S)$}

From the experimental results, average breakdown voltage (BDV) of fresh oil sample is low, as shown in figure 1 (55.6 $\mathrm{kV}$ for PPO, 46.7 in MO), as fresh oil sample contains higher moisture content than that of others. On the other hand, average BDV for 180 days of aged PPO sample is 61, $59 \mathrm{kV}$ for $\mathrm{MO}$ as shown in figure 2 . As of thermal aging process the moisture content of the oil sample is effectively reduced. The average BDV with a catalyst added PPO sample is $69 \mathrm{kV}$ which is much higher than the MO as shown in figure 3. Because MO consists of hydrocarbon component with different composition it reacts with oxygen and produces carbon monoxide, carbon dioxide, hydrogen and sludge which have effectively reduced breakdown strength [9]. In contrast, PPO oil has a higher amount of unsaturated fatty acids $[10,11]$ due to this, the viscosity of PPO is high compared to that of MO, this viscosity limits the particle movement inside the oil [12].

\subsection{Dielectric dissipation factor (DDF)}

The dielectric dissipation factor of both the oil samples has increased with aging as shown in figure 4 . The operating temperature causes dissociation of the oil molecules and therefore decreases the oil viscosity. As a result, the dissociated oil molecules move easily in the oil, which increases the conductivity of the oil samples [13]. For all examined temperature, the DDF of mineral oil with catalytic (MOWC) is higher than that of pongamia pinnata oil with catalytic (PPOWC), because the MO are mainly composed of hydrocarbon molecules with 15-40 carbon atoms per molecule and also these molecules are composed of $\mathrm{C}-\mathrm{C}$ and $\mathrm{C}-\mathrm{H}$ bonds. Due to thermal stress, the chemical bonds between the atoms get broken [14].

In contrast, PPO is made up of triglyceride structure. It has more than $70 \%$ of unsaturated fatty acids as shown in table 1 and so the viscosity of PPOWC oil is higher, when compared to MOWC [10]. This restricts the dissociation of oil molecules in the oil. As a result, the conductivity of the oil becomes low and consequently, DDF of oil also becomes low.

\subsection{Dielectric constant (DC)}

The PPO has a polar nature, whereas MO is polar alkane molecule, which influences the dielectric constant of the oil samples. From the experimental analysis the dielectric constant of PPOWC is higher than that of MOWC as shown in figure 5. The dielectric constants of both the oil samples have decreased with aging. Since it reduces the density of the oil and also viscosity, it leads to increase in the kinetic energy of moving segment present in the oil samples and also it reduces the dipole orientation of the oil samples, resulting in low dielectric constant $[13,15]$.

\subsection{Specific resistivity}

The specific resistivity of MOWC oil gradually decreases when the temperature rises. It has a direct relationship with the interfacial tension and the dielectric loss factor [16]. When the oil has low resistivity, it increases the conductivity and reduces the breakdown strength of the oil. Here, PPO has a much higher resistivity than the MO shown in figure 6 which implies that PPO contamination rate is low when compared to that in $\mathrm{MO}$ for same sampling periods. 
Table 1. Comparison of measured properties of PPO and MO.

\begin{tabular}{|c|c|c|c|c|}
\hline Test & Standard & Limit & PPO & MO \\
\hline \multicolumn{5}{|l|}{ Break down voltage } \\
\hline in $\mathrm{kV}$ & IEC 60156 & Min 35 & 62 & 57 \\
\hline \multicolumn{5}{|l|}{ Dielectric dissipation factor } \\
\hline at $90^{\circ} \mathrm{C}$ & IEC 60247 & Max 0.05 & 0.00825 & 0.012 \\
\hline Dielectric constant & IEC 60247 & $2.8-3.3$ & 3.1 & 2.6 \\
\hline \multicolumn{5}{|l|}{ Specific resistivity in $\Omega \mathrm{m}$} \\
\hline at $90^{\circ} \mathrm{C}$ & IEC 60247 & Min $0.2 \times 10^{12}$ & $12 \times 10^{13}$ & $10^{13}$ \\
\hline \multicolumn{5}{|l|}{ Water content in ppm } \\
\hline at $25^{\circ} \mathrm{C}$ & & & 60 & 27 \\
\hline at $40^{\circ} \mathrm{C}$ & IEC 60814 & Max 200 & 31 & 17 \\
\hline at $90^{\circ} \mathrm{C}$ & & & 15 & 8 \\
\hline \multicolumn{5}{|l|}{ Acidity } \\
\hline in $\mathrm{mgKOH} / \mathrm{g}$ & IEC 62021 & Max 0.06 & 0.78 & 0.09 \\
\hline \multicolumn{5}{|l|}{ Interfacial tension } \\
\hline in $\mathrm{mN} / \mathrm{m}$ & IS 6104 & 0.04 & 11 & 42 \\
\hline \multicolumn{5}{|l|}{ Flash point } \\
\hline in ${ }^{\circ} \mathrm{C}$ & IS 1448 & Min 140 & 245 & 210 \\
\hline \multicolumn{5}{|l|}{ Density in $\mathrm{g} / \mathrm{cm}^{3}$} \\
\hline at $20^{\circ} \mathrm{C}$ & & & 0.924 & 0.85 \\
\hline at $40^{\circ} \mathrm{C}$ & IS 3675 & $\operatorname{Max} 1.0$ & 0.872 & 0.76 \\
\hline at $90^{\circ} \mathrm{C}$ & & & 0.65 & 0.432 \\
\hline \multicolumn{5}{|l|}{ Kinematic viscosity in $\mathrm{cSt}$} \\
\hline at $27^{\circ} \mathrm{C}$ & & & 40 & 12 \\
\hline at $40^{\circ} \mathrm{C}$ & IS 1448 & Max 50 & 27 & 8 \\
\hline at $90^{\circ} \mathrm{C}$ & & & 14 & 6 \\
\hline
\end{tabular}

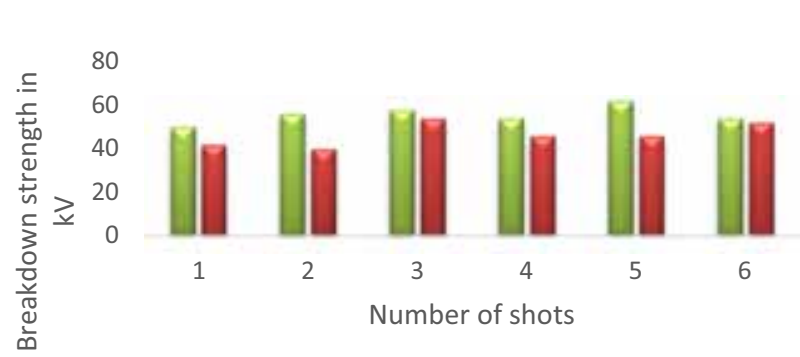

$\square B D V$ of new PPO in $\mathrm{kV} \quad \mathbf{B} D \mathrm{~B}$ of new $\mathrm{MO}$ in $\mathrm{kV}$

Figure 1. BS of new PPO vs BS of MO.

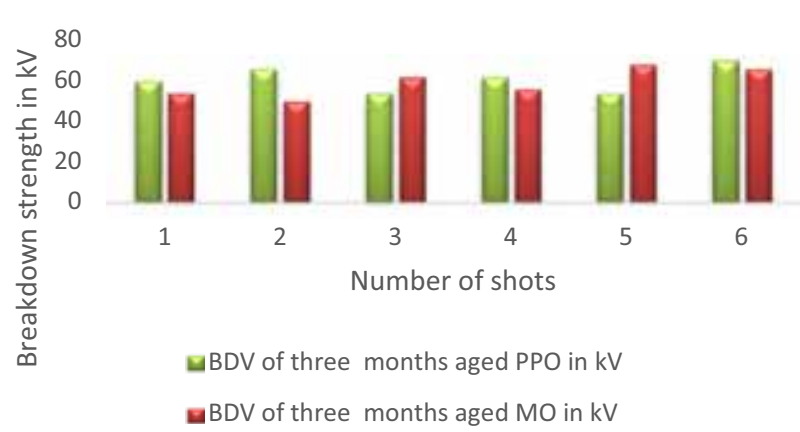

Figure 2. BS of three months aged PPO vs BS of three months aged MO.

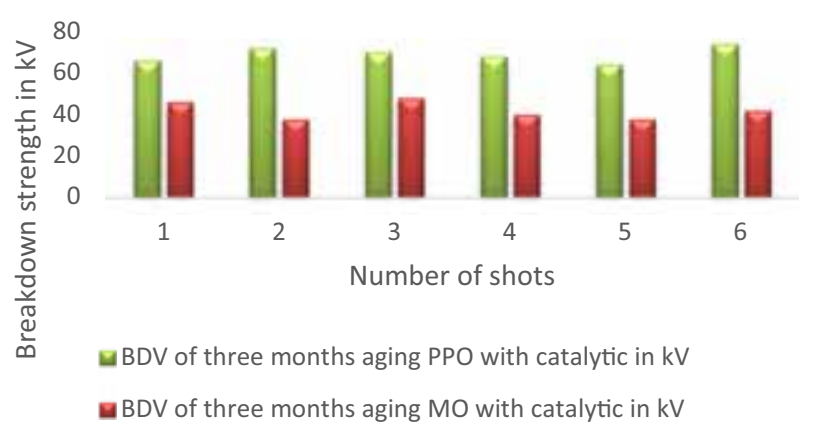

Figure 3. BS of three months aged PPOWC vs BS of three months aged MOWC.

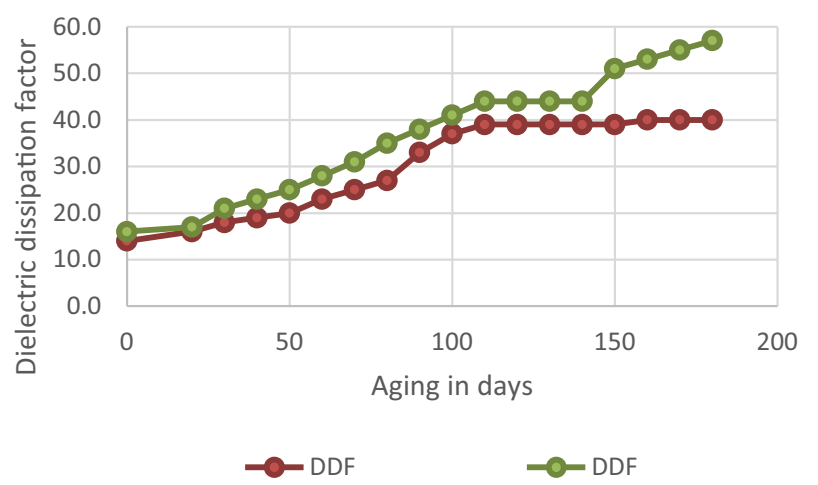

Figure 4. Dielectric dissipation factor vs aging in days. 


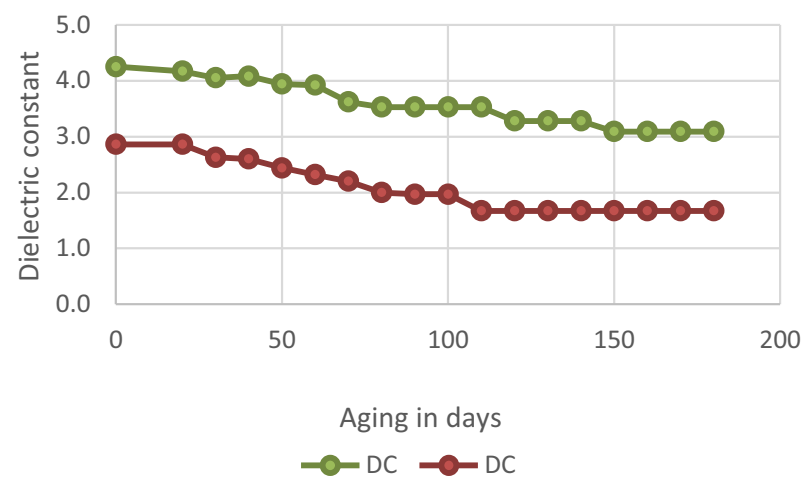

Figure 5. Dielectric constant vs aging in days.

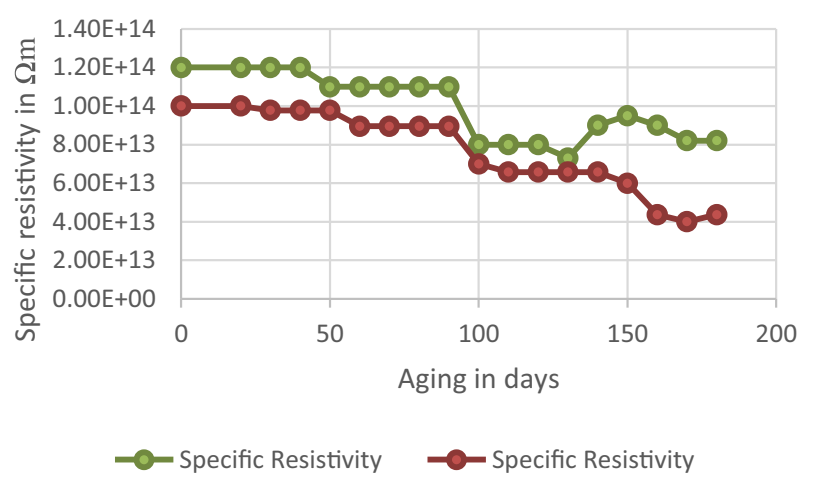

Figure 6. Specific resistivity vs aging in days.

\subsection{Water content analysis}

The water content is a highly influencing factor for electrical characteristics of insulating oil. Here the water content of oil sample is measured by the Karly Fischer titration method. The results show that at all sampling intervals, the water content of PPOWC is much higher than that of the MOWC sample, as shown in figure 7. Up to 120 days, the water content of PPOWC sample got significantly increased beyond that, it decreases with increase in aging.

Whereas, in MOWC sample water content is saturated after 50 days of sampling intervals, because moisture saturation limit of PPOWC is much higher than that of mineral oil. When it reaches to moisture saturation limit the cellulosic insulation used with oil sample absorbs water from PPOWC for maintaining equilibrium condition. Hence, after 120 days of sampling period, the water content of PPOWC gets reduced. Even though, the investigated electrical characteristics of PPOWC are better than mineral oil, mineral oil has high relative moisture content than pongamia pinnata oil $[8,17,18]$.

\subsection{Total acid number}

During aging, acid generation in PPOWC added oil sample is higher than that of MOWC oil samples, as shown in

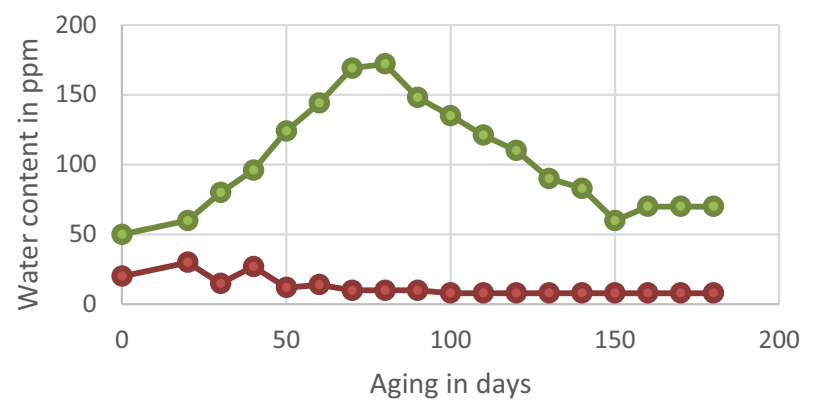

- Water Content $\quad$ - Water Content

Figure 7. Water content vs aging in days.

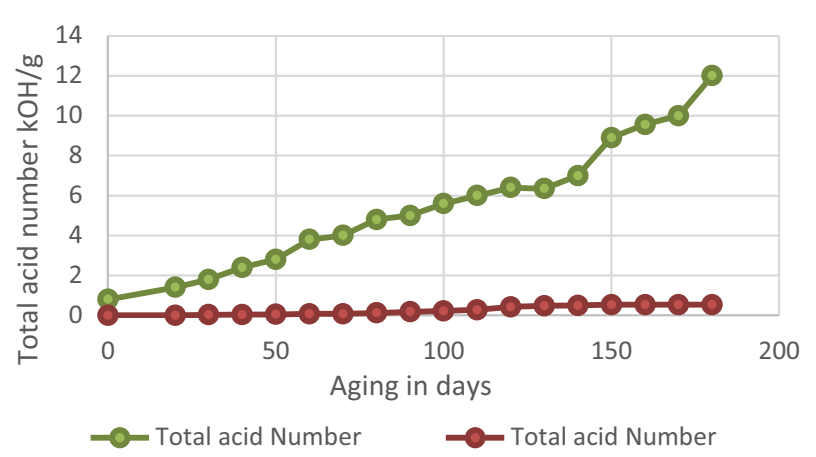

Figure 8. Total acid number vs aging in days.

figure 8. It does not influence the aging of paper. Since the acid generation phenomenon in PPO is different than in MO. In contrast to PPO, acid formation in MO follows chain-off, chain-continuity and chain-breaking out. The MO has lower molecular weight acids, such as formic, acetic and levulinic acids, whereas PPO has higher amount of oleic acid, linoleic acid which are higher molecular fatty acids. These acids do not accelerate the aging rate of the paper, but the lower molecular weight acids reacts with paper, and hence influences its aging $[8,17]$.

\subsection{Viscosity}

According to Mark-Houwink-Sakurada equation, viscosity of oil is related to the average molecular weight [14]. It is much higher in PPOWC than in MOWC. Aging factor and severe oxidation highly influence the oil viscosity. The viscosity of PPOWC is higher for entire aging periods than that of MOWC [19]. First 90 days of sampling periods viscosity of PPOWC and MOWC sample is not stable as shown in figure 9. Furthermore, the viscosity of oil samples slightly increases. Since thermal aging process could increase contamination such as dust, metal ions on oil samples. 


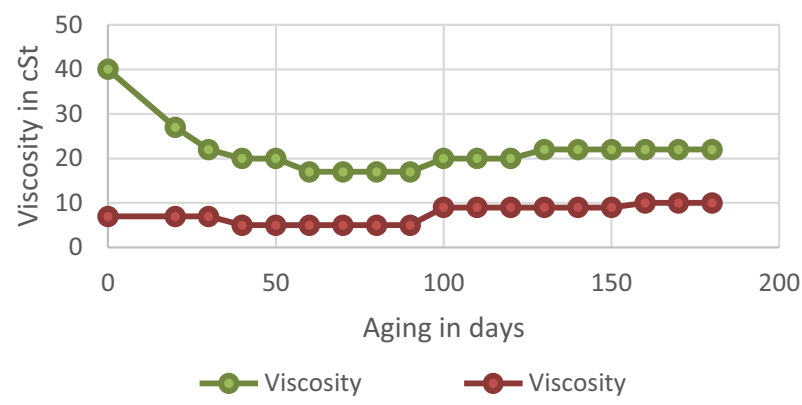

Figure 9. Viscosity vs aging in days.

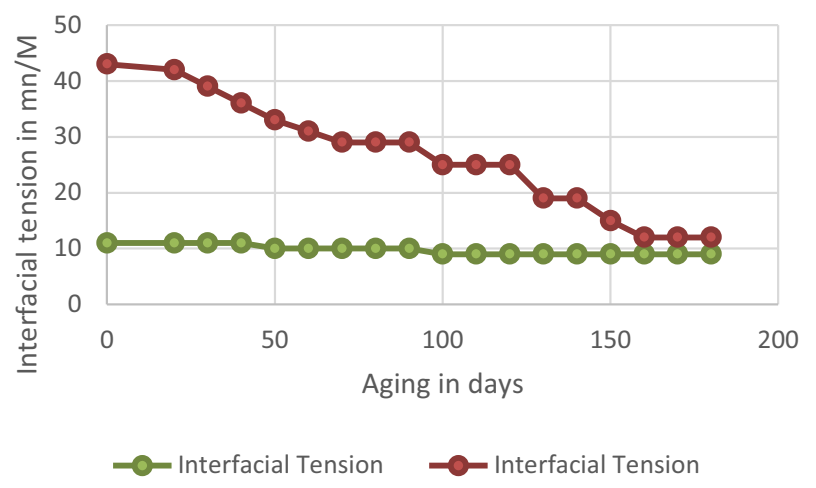

Figure 10. Total acid number vs aging in days.

\subsection{Interfacial tension}

Interfacial tension is the measure of the molecular attractive forces (oil and water) between unlike molecules at the interface. It is used to detect the soluble polar contamination, oil deterioration and oxidation products. The PPO has higher acid content than the MO. Also, the polar content is more than the MO. Hence, interfacial tension of PPOWC is lower than that of MOWC in the same sampling period [16]. The interfacial tension of PPOWC decreases from 11 $\mathrm{mN} / \mathrm{m}$ to $9 \mathrm{mN} / \mathrm{m}$, whereas for MOWC it reduces from 42 $\mathrm{mN} / \mathrm{m}$ to $12 \mathrm{mN} / \mathrm{m}$ respectively as shown in figure 10 . Hence the interfacial tension decreases due to aging that causes thermal degradation in the products of cellulosic insulation as well as in the oil.

\subsection{Flash point}

A flash point is the best indicator that determines the quantity of volatile contamination present in the insulating oil. If the flash point is low, it contains a higher amount of volatile contamination (IEEE Std C57.106 ${ }^{\mathrm{TM}}$, [20]). The experiment result shows that the flash point of PPOWC is $245^{\circ} \mathrm{C}$ which is reduced to $110^{\circ} \mathrm{C}$, at the end of the aging period. In MOWC, the flash point is decreased from $160^{\circ} \mathrm{C}$ to $90^{\circ} \mathrm{C}$ as shown in figure 11 . This implies that, the aging

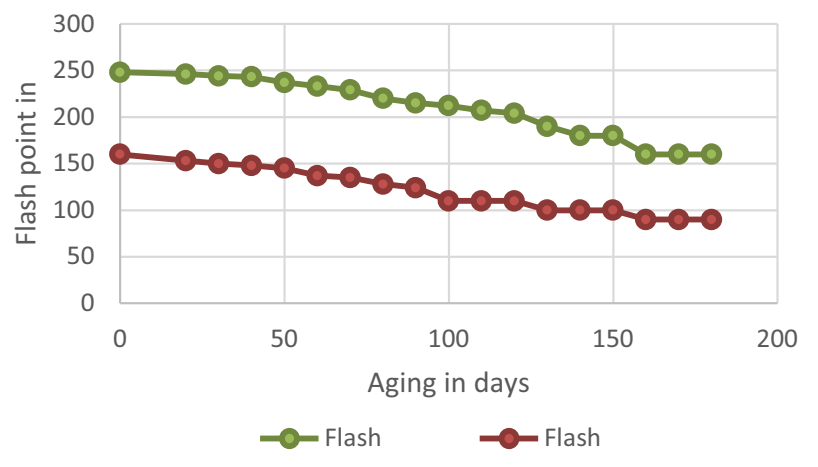

Figure 11. Flash point vs aging in days.

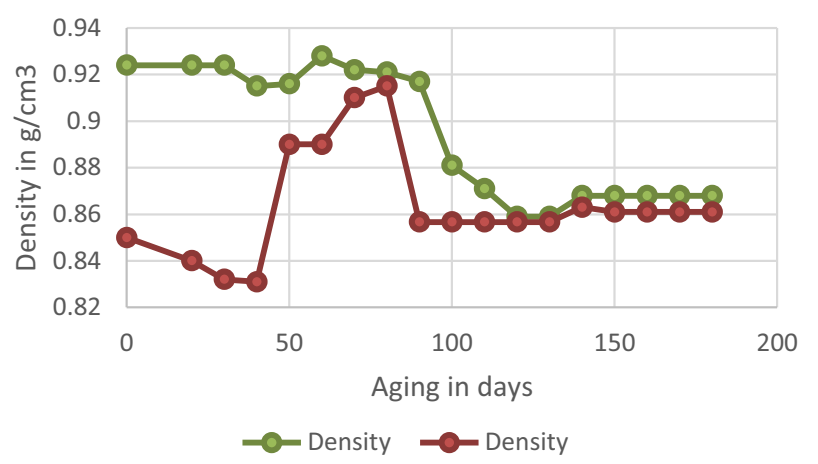

Figure 12. Density vs aging in days.

process significantly reduces the flash point of oil samples [21]. However, the flash point reduction rate in MOWC is more than that of PPOWC, because the accelerated aging process increases the lower molecular weight acids in the MOWC. Lower molecular weight acids reacting with the cellulosic insulation material increases the thermal degradation of cellulosic insulating materials on oil. The higher molecular weight acid generated in PPO does not react with the solid insulating materials, so the thermal aging byproducts are low as compared to MO samples [22].

\subsection{Density}

Initially, the density of PPOWC is higher than that of MOWC. At the first 90 days of sampling period the density of PPOWC is not stable. After some days, it gradually decreases with increase in the aging period that reaches a stable value after 140 days of sampling period. Whereas, the density of MOWC decreases for first 40 days of sampling periods. Yet again the density of PPOWC gradually increases with increase in aging period up to 90 days as shown in figure 12. It induces thermal degradation of insulating oil, paper and the metallic part. In further aging periods, the density gradually gets reduced and finally reaches a more or less stable value samples [16, 22]. 


\section{Conclusions}

Based on the experimental result estimating critical properties of Pongamia Pinnata oil, it emerges that it has satisfied the standard requirements expected of a liquid insulating material. Also, aging performance of PPOWC oil sample is better than that of MOWC oil. The results are encouraging for use of pongamia pinnata oil in distribution transformers. From these experiments pongamia pinnata oil seems to be very good substitution for liquid dielectric in distribution transformer. This also encourages the cultivation of non-edible oil plant in uncultivable waste lands in India.

\section{References}

[1] Fernández I, Ortiz A, Delgado F, Renedo C and Pérez S 2013 Comparative evaluation of alternative fluids for power transformers. Electr. Power Syst. Res. 98: 58-69

[2] Leon Chetty 2013 Vegetable oil based liquid nano composite dielectric. S. Afr. J. Sci. 109: 1-6

[3] Fofana I 201350 years in the development of insulating liquids. IEEE Electr. Insul. Mag. 29(5): 13-25

[4] Martins M A G 2010 Vegetable oils an alternative to MO for power transformers: Experimental study of paper aging in vegetable oil versus MO. IEEE Electr. Insul. Mag. 26(6): $7-13$

[5] Raymon A, Samuel Pakianathan P, Rajamani M P E and Karthik R 2013 Enhancing the critical characteristics of natural esters with antioxidants for power transformer applications. IEEE Trans. Dielectr. Electr. Insul. 20(3): 899-912

[6] Mariprasath T, Ramkumar S and Kirubakaran V 2014, Utilization of pungamia pinnata oil a viable source of Ic Engine And DT: A critical study. Int. J. Adv. Technol. Eng. Res. 24-28

[7] Mariprasath T and Kirubakaran V 2015 Pongamia Pinnata as alternate liquid dielectrics in distribution transformer: a critical study on the property of viscosity. Adv. Energy Power 3(1): 1-7

[8] Liao R, Hao J, Chen G, Ma Z and Yang L 2011 A comparative study of physicochemical dielectric and thermal properties of pressboard insulation impregnated with natural ester and MO. IEEE Trans. Dielectr. Electr. Insul. 18(5): $1126-1137$
[9] Jeong J-I, An J-S and Huh C-S 2012 Accelerated aging effects of mineral and vegetable transformer oils on medium voltage power transformers. IEEE Trans. Dielectr. Electr. Insul. 19(1): 156-161

[10] Dwivedi G and Sharma M P 2013 Cold flow properties of non edible oil in India. Int. J. Appl. Eng. Res. 8(11): 1945-1952

[11] ManjuBala Nag T N, Sandeep Kumar, Manmohan Vyas, Arun Kumar and Bhogal N S 2011 Proximate composition and fatty acid profile of pongamia pinnata a potential biodiesel crop. J. Am. Oil Chem. Soc. 88(4): 559-562

[12] Wang X and Wang Z D 2012 Study of dielectric behaviour of ester transformer liquids under AC voltage. IEEE Trans. Dielectr. Electr. Insul. 19(6): 1911-1925

[13] Rajab A, Sulaeman A, Sudirham S, Suwarno S 2011 A comparison of dielectric properties of palm oil with mineral and synthetic types insulating liquid under temperature variation. ITB J. Eng. Sci. 43: 191-128

[14] Xu Y, Qian S, Liu Q and Wang Z D 2014 Oxidation stability assessment of a vegetable transformer oil under thermal aging. IEEE Trans. Dielectr. Electr. Insul. 21(2): 683-692

[15] Shah Z H and Tahir Q A 2011 Dielectric properties of vegetable oils. J. Sci. Res. 3: 481-492

[16] Kohtoh M, Kaneko S, Okabe S, Amimoto T 2009 Aging effect on electrical characteristics of insulating oil in field transformer. IEEE Trans. Dielectr. Electr. Insul. 11(6): 1198-1706

[17] Singha S, Asano R, Frimpong G, Claiborne C and Cherry D 2014 Comparative aging characteristics between a high oleic natural ester dielectric liquid and MO. IEEE Trans. Dielectr. Electr. Insul. 21(1): 49-58

[18] Yao S, Li J, Li L, Liao R and Zhou J 2014 Comparison analysis to thermal aging properties of vegetable and mineral insulating oils. In: IEEE International conference on high voltage engineering application, $\mathrm{pp} .1-4$

[19] Abdi A, Boubakeur A, Haddad A and Harid N 2011 Influence of artificial thermal aging on transformer oil properties. Electr. Power Compon. Syst. 39: 1701-1711

[20] IEEE Guide for Acceptance and Maintenance of Insulating Oil in Equipment. IEEE Std C57.106 ${ }^{\mathrm{TM}} 2007$

[21] Matharage B S H M S Y, Fernando M A R M, Bandara M A A P, Jayantha G A, Kalpage C S 2013 Performance of coconut oil as an alternative transformer liquid insulation. IEEE Trans. Dielectr. Electr. Insul. 20(3): 887-898

[22] Azis N and Wang Z D 2011 Acid generation study of natural ester. In: Symposium on high voltage engineering, Hannover, Germany, pp. 1-6 